\title{
The Role of Sacral Nerve Stimulation in Female Pelvic Floor Disorders
}

\author{
Baydaa Al-Sannan • Mai Banakhar • \\ Magdy M. Hassouna
}

Published online: 8 August 2013

(C) Springer Science+Business Media New York 2013

\begin{abstract}
Female pelvic floor disorders, such as urge incontinence, nonobstructive urinary retention, painful bladder syndrome, fecal incontinence, chronic constipation, and sexual dysfunction, represent multiple challenges to the treating physicians. Sacral nerve modulation (SNM) gives a promising alternative and a minimally invasive treatment option for chronic pelvic floor disorders resistant to conventional treatment. This review covers the mechanism of action and surgical procedure of the SNM as well as the current and expanding indications for SNM in female pelvic floor disorders.
\end{abstract}

Keywords Sacral nerve modulation · Percutaneous nerve evaluation · Urgency-frequency $\cdot$ Urge incontinence $\cdot$ Urinary retention $\cdot$ Fecal incontinence $\cdot$ Urinary incontinence

\section{Introduction}

The female lower urinary tract (LUT) and pelvis are innervated by three nervous systems: parasympathetic, sympathetic, and somatic. The parasympathetic system via the pelvic nerve (S2 to S4) activates the detrusor muscle of the bladder as well as inhibits the urethral sphincteric mechanism, favoring voiding. The sympathetic contributions originate from $\mathrm{T} 12$

\section{B. Al-Sannan}

London Health Sciences Center, Victoria Hospital, University of

Western Ontario, London ontario, ON N6A 5W9, Canada

e-mail: baidaakw_dr@hotmail.com

\section{Banakhar}

Faculty of Medicine, King Abdulaziz University, Jeddah, Saudi

Arabia

M. M. Hassouna $(\square)$

Toronto Western Hospital, University Health Network, Toronto, ON M5G 2C4, Canada

e-mail:magdy.hassouna@uhn.on.ca to L1 and inhibit the bladder while activating the urethra, thus favoring storage. The somatic innervation, through the pudendal nerve (S2 to S4) regulates the urethra and pelvic floor muscles.

The first (SNM) procedure was performed in 1982 by Tanagho and Schmidt at the University of California in San Francisco [1]. The U.S. Food and Drug Administration (FDA) approved SNM for three chronic voiding dysfunction conditions: intractable urge incontinence in 1997, urgency- frequency, and nonobstructive urinary retention in 1999 [2]. Patients who have failed to respond or could not tolerate conservative treatments [3] are offered SNM therapy. In 2011, the FDA approved SNM for chronic fecal incontinence in patients who have failed or could not tolerate conservative treatment. The efficacy of SNM for the treatment of chronic constipation, interstitial cystitis/painful bladder syndrome, pelvic floor muscle dysfunctions, sexual dysfunctions, and vulvar disorders have been explored since the FDA approval.

\section{Mechanism of Action}

The exact working mechanism of SNM is not yet fully understood. SNM probably has an impact one or more neuronal reflexes [4-7]: by inhibiting the spinal tract neurons involved in the micturition reflex as well as the neurons involved in spinal segmental reflexes, namely through stimulation of the afferent component of the same spinal segment. There is evidence of direct inhibition of postganglionic neurons and primary afferent pathways in one study on the pudendal nerve [5].

In fecal incontinence, Vitton et al. [8] described evidence of a somatosympathetic reflex pathway, which could explain the reasons why fecal incontinence treatment using SNM, leading to reduced colonic activity and increased tonus of the anal sphincter complex, may be successful [9]. 


\section{Surgical Techniques for SNM Implantation}

The following is a summary of the surgical technique [10 $]$. A complete clinical evaluation should be undertaken, including history, physical examination, a voiding diary for minimum of 3 days at baseline, and possibly urodynamic assessment. Associated symptoms, such as pelvic pain and bowel symptoms, also should be assessed with the help of visual analogue scale and number of episodes of FI per week. The voiding parameters in the diary will be compared before and after the evaluation test to assess the objective response. Patients are counseled for the sacral nerve stimulation procedure risks and benefits. One should ensure that there are no contraindications for SNM (Table 1) [9].

The first crucial step in determining if the patient is a good candidate for definite implant is a test stimulation trial. Test stimulation can be either percutaneous nerve evaluation (PNE) or staged implant.

\section{PNE}

In the 1990s, Schmidt et al. devised a simple outpatient diagnostic test that involved percutaneous placement of a wire to stimulate the S3 nerve root and evaluate motor and sensory responses.

Table 1 Relative contraindications for sacral nerve stimulation (adapted from [9])

\begin{tabular}{|c|c|}
\hline \multirow[t]{6}{*}{ Urologic } & - Lower urinary tract obstruction \\
\hline & - Urinary tract infection explaining symptoms \\
\hline & - Stress urinary incontinence \\
\hline & - Bladder calculi or tumors \\
\hline & - Carcinoma in situ \\
\hline & - Ureteral calculi \\
\hline \multirow[t]{3}{*}{ Gynecologic } & - Malignancies or infections \\
\hline & - Prolapse that might explain symptoms \\
\hline & - Pregnancy \\
\hline \multirow[t]{2}{*}{ Gastroenterologic } & - Malignancies \\
\hline & - Infections that might explain symptoms \\
\hline \multirow[t]{3}{*}{ Neurologic } & - Any undiagnosed or not yet managed neuropathy \\
\hline & - Convulsive disorders \\
\hline & - Cognitive impairment \\
\hline \multirow[t]{2}{*}{ Orthopedic } & - Bony abnormalities of the sacrum, spina bifida \\
\hline & - Difficult or impossible transforaminal access \\
\hline \multirow[t]{2}{*}{ Job-related } & - Heavy-duty jobs \\
\hline & - Working within electrical or magnetic fields \\
\hline \multirow[t]{2}{*}{ Sports } & $\begin{array}{l}\text { - Parachute jumpers, fight sports, most professional } \\
\text { sports }\end{array}$ \\
\hline & $\begin{array}{l}\text { - Diving (safe down to } 20 \mathrm{~m} \text {; deformation seen from } \\
40 \mathrm{~m} \text { ) }\end{array}$ \\
\hline
\end{tabular}

PNE is an office-based technique; an insulated thin temporary monopolar lead is placed into the third sacral nerve S3 foramen under local anesthesia with the patient in the prone position. In our center, we utilize $1 \%$ plain lidocaine as a local anesthesia. The S3 foramen can be found $2-3 \mathrm{~cm}$ off the midline at the level of the sciatic notch. Placement of bilateral S3 foramen needles can be accomplished either using bony landmarks and/or fluoroscopy. Once the foramen needles are placed (either $3^{1 / 2}$ or $5 \mathrm{inch}$ ), they are stimulated using an external pulse generator, and the side giving better response is chosen for the subchronic test. Responses signaling correct placement include bellows contraction of the pelvic floor and plantar flexion of the great toe (Table 2). With the PNE test, the patient will be able to confirm correct placement by the tingling sensation in rectum, vagina, scrotum, and/or perineum. Once the appropriate side and position selected, the temporary unipolar lead is connected to an external pulse generator and taped to the skin surface for the test period. Often, bilateral PNE leads are placed during the testing phase.

Pre- and post-PNE test voiding diaries are completed to assess symptoms response. Patients who demonstrate a minimum of a $50 \%$ symptom improvement from baseline are considered candidates for placement of the permanent quadripolar lead and implantable pulse generator. The temporary leads of the PNE test are easily removed in the office once the test phase is complete, typically in 3 to 7 days [11•]. The duration of this test is limited to a maximum of 2 weeks due to increase risk of lead contamination and infection [12]; however, no prophylactic antibiotic is required during the PNE trial. During the test period, the patient is advised to restricted physical activities

Limitations of the PNE include mainly lead migration. Short-term test stimulation period as well as and this probably explains the relatively low success rate of PNE, estimated at approximately $50 \%[13,14]$. Everaert et al. recorded falsepositive PNE in $33 \%$ of cases in home patients who have beneficial test stimulation with a temporary lead and did not continue to have a successful outcome after the permanent lead implantation [15].

Table 2 Sacral roots, motor and sensory response [55]

\begin{tabular}{lll}
\hline $\begin{array}{l}\text { Nerve } \\
\text { root }\end{array}$ & Motor response & Sensory response \\
\hline S2 & $\begin{array}{c}\text { Anal sphincter contraction (A-P } \\
\text { pinching of perineum/coccyx), leg/ } / \\
\text { heel rotation, planter flexion of } \\
\text { foot, calf contraction }\end{array}$ & $\begin{array}{c}\text { Sensory alteration of the } \\
\text { base of penis or vagina }\end{array}$ \\
S3 & $\begin{array}{c}\text { Bellows reflex (inwards } \\
\text { contractions), plantar flexion of } \\
\text { great toe }\end{array}$ & $\begin{array}{c}\text { Rectal sensation, } \\
\text { extending into scrotum } \\
\text { or labia }\end{array}$ \\
S4 & Bellows reflex & Rectal sensation only \\
\hline
\end{tabular}




\section{A Quadripolar tinned lead}
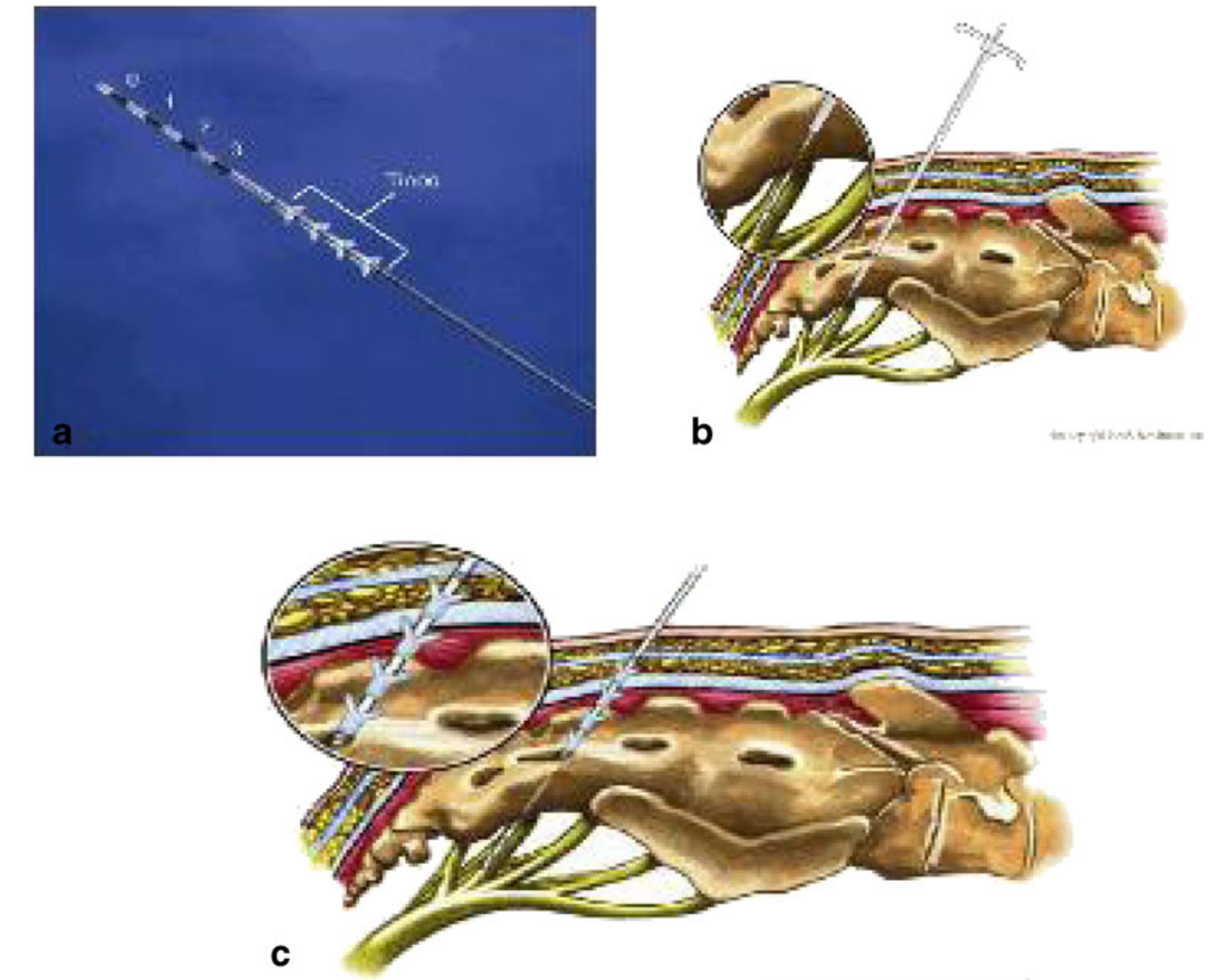

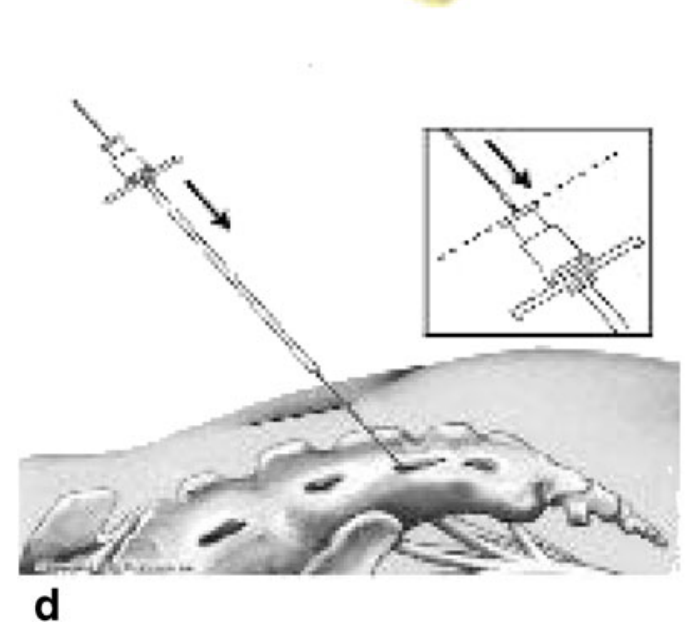

Fig. 1 A Quadripolar tinned lead, the electrodes are shown. B Sacral foramen needle is inserted and guided to the desired location. C Location is verified by electrical stimulation to the needle, and the fluoroscopy is used to confirm the position of the needle in the $\mathrm{S} 3$ foramen. D The metal

\section{Staged Implant}

Janknegt first described the staged implant approach where an implanted chronic lead, rather than the temporary lead,

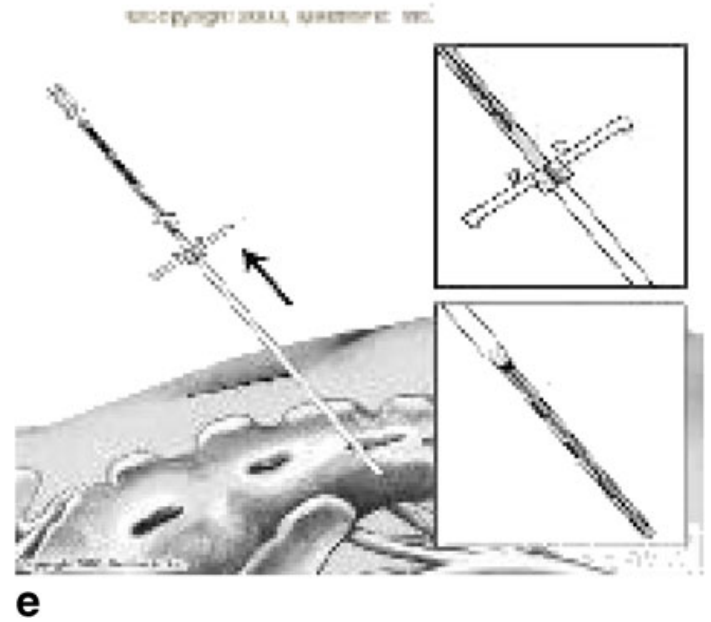

dilator is removed and the plastic dilator is positioned. $\mathbf{E}$ The quadripolar lead is introduced through the dilator plastic sheath into position which is confirmed by stimulation, the plastic dilator sheath in withdrawn carefully under fluoroscopic guidance. Pictures adapted from Metronic Inc, 2003

was placed for initial testing [16]. This approach is indicated for the patients who are not a candidate for officebased PNE test stimulation (e.g., obese, difficult anatomy, previous sacral surgery, or unable to tolerate the procedure 
Fig. 2 A Fluoroscopic view of the sacral foramens. B Permanent electrode leads position. C A-P view of the electrode position. D IPG position. Pictures adapted from Medtronic Inc, 2003

\section{A Fluoroscopic images of sacral foramens and Permanent electrode leads}

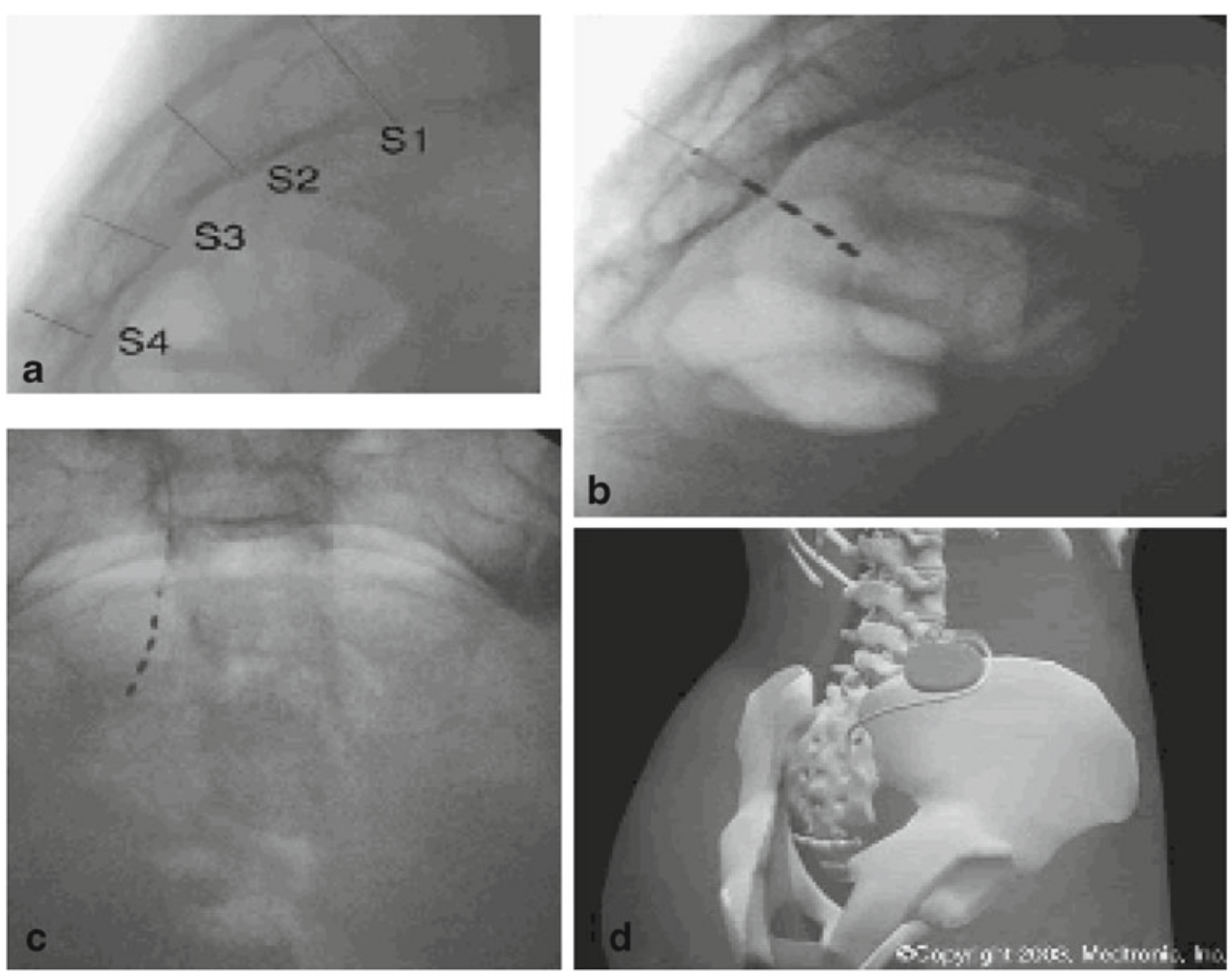

under local anesthesia) or did not respond to the PNE test. The stimulation test is performed in the operating room as a first stage of two-stage implant. In patients with doubtful PNEs test result, a two-stage implant is suggested to increase the yield of screening patients to $70 \%$ for a permanent implant [17].

In case of general anesthesia, the anesthetist is reminded to avoid any long-acting muscle relaxants, which may impair sacral nerve stimulation or visualization of motor response. Fluoroscopy imaging is used to help in placement confirmation of the quadripolar permanent lead (Figs. 1 and 2). A test period of 14 days is used to determine which patient meets the criteria to have the permanent implant if he is a good candidate for the therapy based on the response in the voiding diary.

\section{Chronic Implant}

The implantation of the implantable pulse generator (IPG) can be performed under local or general anesthesia. Once the quadripolar permanent lead is inserted into S3 foramen the lead is then tunneled deeply through the subcutaneous fat typically to the ipsilateral upper buttock. However, depending on the patients' dominant hand side, she may have a preference for the location the chronic implantable pulse generator (IPG).
The advantages and disadvantages for one stage versus two-stage procedure summarized in Table 3.

\section{Current Indications for SNM}

Intractable Urge Incontinence

Overactive bladder $(\mathrm{OAB})$ is defined as urinary urgency, frequency, and nocturia, with or without urinary incontinence, and with no proven infection or other obvious disorder. Of those patients with $\mathrm{OAB}$, up to $37.2 \%$ have urge urinary incontinence.

Schmidt et al. [18] reported on Sacral neuromodulation therapy in 76 patients with refractory urge incontinence from 16 centers worldwide during the 6-month study period. Of the 34 patients receiving active SNM therapy compared with the delayed group, $16(47 \%)$ were completely dry and an additional $10(29 \%)$ demonstrated a more than $50 \%$ reduction of incontinence episodes.

In a 5-year, prospective, multicenter trial, Van Kerrebroeck et al. evaluated the long-term efficacy and safety of SNM in patients with urge incontinence. The mean leaking episodes per day decreased from $9.6 \pm 6.0$ to $3.9 \pm 4.0$ with $68 \%$ successful outcome at 5 years [19॰]. Other randomized trials 
Table 3 Comparison between the advantages and disadvantages of oneversus two-stage implant procedures [56]

\begin{tabular}{|c|c|c|}
\hline & PNE (one-stage) & Tined lead (two-stage) \\
\hline \multirow[t]{6}{*}{ Advantages } & $\begin{array}{l}\text { - Office procedure, under } \\
\text { local anesthesia }\end{array}$ & $\begin{array}{l}\text { - Less risk of lead } \\
\text { migration during the test } \\
\text { trial }\end{array}$ \\
\hline & $\begin{array}{l}\text { - Greater patient } \\
\text { acceptance }\end{array}$ & $\begin{array}{l}\text { - Greater comfort due to } \\
\text { level of sedation for } \\
\text { anxious or pain focused } \\
\text { patients }\end{array}$ \\
\hline & $\begin{array}{l}\text { - Office removal of the } \\
\text { leads }\end{array}$ & $\begin{array}{l}\text { - Quadripolar lead } \\
\text { configuration allows for } \\
\text { more precise placement } \\
\text { and programming }\end{array}$ \\
\hline & $\begin{array}{l}\text { - Accurate patient } \\
\text { sensation feedback } \\
\text { during insertion }\end{array}$ & $\begin{array}{l}\text { - Symptoms improvement } \\
\text { remains unchanged } \\
\text { when converted to } \\
\text { chronic implant }\end{array}$ \\
\hline & $\begin{array}{l}\text { - Less costly, more } \\
\text { favorable } \\
\text { reimbursement }\end{array}$ & $\begin{array}{l}\text { - Longer trial period to } \\
\text { assess for symptoms } \\
\text { improvement }\end{array}$ \\
\hline & $\begin{array}{l}\text { - Less risk of infection } \\
\text { because permanent lead } \\
\text { and IPG will be placed } \\
\text { in one sitting after } \\
\text { successful PNE }\end{array}$ & $\begin{array}{l}\text { - Higher rate of true } \\
\text { positives }\end{array}$ \\
\hline \multirow[t]{3}{*}{ Disadvantages } & $\begin{array}{l}\text { - Higher rate of false } \\
\text { negatives, must do } \\
\text { staged implant if } \\
\text { equivocal }\end{array}$ & $\begin{array}{l}\text { - Requires two surgeries } \\
\text { even if trial is } \\
\text { unsuccessful }\end{array}$ \\
\hline & $\begin{array}{l}\text { - Potential to place } \\
\text { permanent lead in less } \\
\text { favorable location, thus } \\
\text { requiring reoperation }\end{array}$ & $\begin{array}{l}\text { - Greater potential for } \\
\text { infection due to } \\
\text { increased length of trial } \\
\text { and potential } \\
\text { contamination of } \\
\text { permanent lead }\end{array}$ \\
\hline & & $\begin{array}{l}\text { - More expensive if the trial } \\
\text { is unsuccessful }\end{array}$ \\
\hline
\end{tabular}

showed evidence of a clear beneficial effect of the immediate implant at 6 months particularly in the number of total micturition and leakage episodes, the number of pads used, the rating of urgency, the maximum bladder capacity, and volume at first detrusor contraction, as well as on quality of life $[20,21 \bullet]$.

\section{Urgency-Frequency}

Urinary frequency-urgency syndrome is used to identify a patient group who suffer from urinary frequency and urgency at the same time with or without a pain component.

Hassouna et al. [22] in 2000 reported the outcomes of SNM on refractory urgency-frequency conditions in 51 patients from 12 centers during an initial 6-month period extended to 2 years. Outcomes at 6 months in the active SNM group showed improvement in the number of daily voids $(16.9 \pm 9.7$ to $9.3 \pm 5.1)$, volume voided $(118 \pm 74 \mathrm{~mL} / \mathrm{s}$ to $226 \pm 124 \mathrm{~mL} / \mathrm{s}$,) degree of urgency (rank score, $2.2 \pm 0.6$ to $1.6 \pm 0.9$ ), and Short-Form 36 (SF-36) quality-of-life measure.

Patients with urgency frequency syndrome had $56 \%$ successful outcome 5 years after the SNM. The mean voids per day decreased from $19.3 \pm 7.0$ to $14.8 \pm 7.6$, and mean volume voided per void increased from $92.3 \pm 52.8$ to $165.2 \pm 147.7 \mathrm{~mL}$ [19•].

\section{Nonobstructive Urinary Retention}

Stimulation of the $\mathrm{S} 3$ has been shown to be effective in stimulating the urethral sphincter [23]. A large, multicenter (Medtronic MDT-103; USA, Canada, and Europe), prospective, randomized, clinical trial looked at the efficacy and safety of chronic neuromodulation to the S3 nerve. Results of this study led to approval by the FDA in October 1997.

Van Kerrebroeck et al. evaluated 152 patients 5 years after SNM implantation: $20.4 \%$ patients with retention. The mean volume per catheterization decreased from $379.9 \pm 183.8$ to $109.2 \pm 184.3 \mathrm{~mL}$, and the mean number of catheterizations decreased from $5.3 \pm 2.8$ to $1.9 \pm 2.8$ with $71 \%$ patients with retention had successful outcomes [19•].

Shaker and Hassouna reported 20 patients with urinary retention who showed significant improvement (postvoid residual decreased from $78 \%$ to $10 \%$ of total urinary output), with a mean follow-up of 15 months [2]. Denzinger et al. reviewed 20 patients, of whom $80 \%$ were female, who suffered from idiopathic or neurogenic urinary retention for a median 60 months before SNM; $90 \%$ of the stimulated patients showed significant success with implantation of IPG within a median of 43 days. Postvoid residual (PVR) urine was reduced significantly from a median of $350 \mathrm{~mL}$ to $135 \mathrm{~mL}$ $[24 \bullet]$.

\section{Fecal Incontinence}

Fecal incontinence (FI) is defined as uncontrollable loss of feces from the bowel and affects $0.4-18 \%$ of the adult population. It can be due to anatomical or neurologic damage of the anal sphincter mechanism, idiopathic degeneration of the anal sphincters, or secondary to nonsphincter causes (i.e., dementia, diarrhea).

Wexner et al. evaluated a total of 133 patients with a mean duration of fecal incontinence of 6.8 years. Of these, 119 patients $(90 \%)$ had a successful test stimulation $\geq 50 \%$ and received a permanent implant. At 12 months, $83 \%$ of subjects achieved therapeutic success and $41 \%$ achieved $100 \%$ fecal continence. Therapeutic success was $85 \%$ at 24 months. Incontinent episodes decreased from a mean of 9.4 per week at baseline to 1.9 at 12 months and 2.9 at 2 years [25]. At 3 years follow-up, $86 \%$ of patients reported $\geq 50 \%$ reduction in the number of FI episodes per week compared with baseline 
and the number of FI per week decreased from a mean of 9.4 at baseline to 1.7. Perfect continence was achieved in $40 \%$ of subjects [26].

Uludağ et al. reported the long-term outcome and quality of life in 50 patients with FI who had permanent SNM implant. Initial improvement in continence with SNM was sustained with success rate of $80 \%$ at 7 years [27•].

Clinical outcome and cost-effectiveness were analyzed in a prospective, multicenter, cohort study that included 369 consecutive patients with urge urinary and/or FI over duration of 24 months. The SNM significantly improved the continence status and quality of life of patients with urge urinary and/or FI compared with alternative treatments [28•].

\section{Expanding Indications for SNM}

\section{Painful Bladder Syndrome and Chronic Pelvic Pain}

Painful bladder syndrome (PBS) or interstitial cystitis (IC) is characterized by urinary frequency, urgency, and pelvic pain often localized to the bladder or urethra. The disease is poorly defined and study outcomes often are difficult to compare due to differences in definition. The National Institute of Diabetes and Digestive and Kidney Disease (NIDDK) formulated criteria for a diagnosis of IC in 1987 and 1988 [29].

The International Continence Society (ICS) came with the term "painful bladder syndrome" (PBS) as "the complaint of suprapubic pain related to bladder filling, accompanied by other symptoms, such as increased daytime and night-time frequency, in the absence of proven urinary infection or other obvious pathology" [30].

The term IC is reserved for PBS with typical cystoscopic and histologic features. IC should include some form of inflammation in the deeper layers of the bladder wall [31]. Standard pharmacotherapies often are ineffective and associated with significant side effects. Cystoscopic hydrodistention often provides only temporary relief, and cystectomy and urinary diversion have an unacceptably high failure rate for pain control [32], in addition to being a very invasive option.

Maher et al. evaluated 15 women with refractory IC/PBS who were treated with SNM. Of the 15 women, $73 \%$ reported improvement in pelvic pain, daytime frequency, nocturia, and urgency; $87 \%$ reported a $50 \%$ decrease in bladder pain; and $47 \%$ had a $50 \%$ decrease in $24-\mathrm{h}$ voiding frequency [33].

A recent review evaluated the efficacy and safety of SNM in treating chronic pelvic pain related to IC/PBS [34•]. The average age of the participants ranged from 41 to 60 years in the included studies. The majority were females. Overall, $70.8 \%$ were successful at the trial stage. One study showed an $80 \%$ improvement in Global response assessment score [34•].

Marinkovic et al. reported significant improvement in pelvic pain and urgency with $80 \%$ satisfaction rate. They concluded that SNM provides adequate improvement in IC/ PBS patients with a minimum of 6 years of follow-up [35•].

A total of 78 patients fulfilled the clinical criteria for IC/BPS and showed cystoscopic evidence of glomerulation and/or ulcers. All patients failed conservative management before considering SNM. Permanent SNM, showed at least $50 \%$ improvement in their symptoms with a temporary PNE test. Median follow-up was 61.5 months ( $\mathrm{SD} \pm 27.7)$. Good longterm success of the SNM was seen in $72 \%$ of the patients [36•].

Martellucci et al. evaluated 17 consecutive patients suffering from chronic pelvic pain after pelvic surgeries with SNM; $47 \%$ of patients fulfilled the criteria for permanent implantation and were followed for a mean of 39 months. Using a visual analog pain score, pain levels decreased from 8.2 preoperatively to $1.9,2.1,2.0$, and 1.8 at $6,12,24$ and 36 months, respectively [37॰].

Chronic Constipation and Irritable Bowel Syndrome

Chronic constipation is another disabling bowel dysfunction that can be associated with bloating, abdominal pain, sensation of incomplete emptying, and pelvic organ prolapse in chronic severe cases. In one study of 19 patients suffering from severe rectal outlet obstruction, $42 \%$ reported a significant improvement after SNM in the Wexner constipation scores and quality of life scores compared with the preoperative baseline level [38].

Prospective, multicenter study of 45 female patients who received SNM treatment for chronic constipation, $87 \%$ achieved treatment success after a median 28 months followup [39॰]. The defecation frequency increased from 2.3 to 6.6 evacuations times per week and from 2.3 to 4.8 days per week. Also, a decrease in time spent toileting, straining, perception of incomplete evacuation, and decrease in subjective rating of abdominal pain and bloating [39॰].

Of 45 patients with irritable bowel syndrome, 35 patients improved symptomatically and 34 had enhanced quality of life related to bowel symptoms; $53 \%$ of patients reported an improvement in irritable bowel syndrome-related symptoms after SNM [40].

\section{Female Sexual Dysfunction}

High-tone pelvic floor dysfunction is an important cause of female sexual dysfunctions (FSDs) and is seen in many patients with various pelvic pain and hyperactive pelvic floor disorders, including IC/PBS, vulvodynia, urgency frequency syndrome, urinary retention, dyspareunia, and obstructed defecation syndrome.

Lombardi et al. evaluated the sexual function in females treated with SNM for LUTS by the Female Sexual Function Index (FSFI) and the Female Sexual Distress Score (FSDS). Concluded, The positive effects regarding improvement in 
sexual function index of arousal and lubrication in voiding dysfunction female group [41].

Between May 2003 and December 2008, a prospective study evaluated 30 consecutive female patients (median age 53 years) with OAB underwent SNM on Female Sexual Function index (FSFI). Comparison between preoperative, median midterm follow-up 22.5 months, and median last follow-up 36.3 months visits were performed. Regarding sexuality, the mean improvement was around $30 \%$ at midterm and last follow-up [42•].

Caremel et al. found that SNM improves the quality of sexual activity in $45 \%$ patients. The number of urinary and fecal episodes of incontinence decreased respectively for $50 \%$ and $15 \%$ patients during sexual activity. The quality of sexual life and orgasm score are significantly increased in the group of patients improved on the double incontinence [43•].

Another prospective study of 36 consecutive female patients with pain and LUT symptoms, who underwent SNM, showed that the FSFI scores improved by $52 \%$ at 6-month follow-up [44]. The improvements were better in patients who underwent the treatment for LUT symptoms as compared with those who had pain as their primary complaint.

In a recent case report, SNM showed a beneficial affects in patients with severe vulvar vestibulitis who failed conservative therapy [45]. Another report reveled that SNM resulted in improvements of both LUT symptoms and clitoral pain in a patient $[46 \cdot]$.

These studies demonstrated an evidence of potential benefit of SNM for female sexual disorders, mainly in the presence of urinary and/or bowel disorders [47•]. However, large and good quality studies are needed to demonstrate the full effect of SNM on FSDs.

\section{Complications of SNM}

The SNM study group has published several reports on the efficacy and safety of the procedure for individual indications [48]. A total of 581 patients were recruited and 219 underwent implantation for SNM. The complications were divided into both PNE-related and postimplant-related problems. Of the 914 test stimulation procedures done on the 581 patients, 181 adverse events occurred in 166 of these procedures: $11.8 \%$ related to lead migration; technical problems and pain represented $2.6 \%$ and $2.1 \%$, respectively. For the 219 patients who underwent implantation for the SNM, pain at the neurostimulator site was reported in $15.3 \%$ at 12 months (Table 4). Surgical revisions performed in $33.3 \%$ of cases include relocation of the neurostimulator and revision of the lead for suspected migration. Explantation of the system was performed in $10.5 \%$ for lack of efficacy [48].

Hijaz et al. reported the complications in a review of 214 patients who underwent SNM; 161 underwent IPG
Table 4 Reported complications with sacral neuromodulation therapy from the neuromodulation study group [49]

\begin{tabular}{ll}
\hline Complications & $\begin{array}{l}\text { Probability of occurrence (Siegel } \\
\text { series) }\end{array}$ \\
\hline Pain at the neurostimulation site & $15.3 \%$ \\
New pain & $9 \%$ \\
Suspected lead migration & $8.4 \%$ \\
Infection & $6.1 \%$ \\
Transient electric shock & $5.5 \%$ \\
Pain at lead site & $5.4 \%$ \\
Adverse change in bowel & $3 \%$ \\
$\quad$ function & $1.7 \%$ \\
Technical problems & $1.6 \%$ \\
Suspected device problems & $1 \%$ \\
Change in menstrual cycle & $0.6 \%$ \\
Adverse change in voiding & \\
function & $0.5 \%$ \\
Persistent skin irritation & $0.5 \%$ \\
Suspected nerve injury & $0.5 \%$ \\
Device rejection &
\end{tabular}

implantation and were monitored for a mean follow-up of 16 months. The explantation and revision rate was $10.5 \%$ and $16.1 \%$, respectively. Revisions were performed for decreases in response (17/26), IPG site discomfort (4/26), draining sinus at the IPG site (4/26), and lead migration $(1 / 26)[49]$.

In a study by Spinelli et al. [50], the total infection rate in the whole series was $18 / 180(10 \%)$, which was slightly higher than that reported by the sacral neuromodulation study group (6.1\%) [49].

In a recent study, Pettit et al. reviewed their experience at the Mayo Clinic. The main surgical complication remains to be surgical site infection. They reviewed evidence-based suggestions and procedure-specific techniques and found that the infection rate dropped to less than $2 \%$ [51].

\section{SNM and Pregnancy}

The use of SNM has increased in females of childbearing age with various voiding dysfunctions. Medtronic product technical manual indicates that safety and effectiveness have not been established for pregnancy, the unborn fetus, and delivery. Due to the unknown teratogenic potential of electrical stimulation, it has been considered contraindicated in pregnant women with various voiding dysfunctions.

Wang and Hassouna were first to examine the effect of electrical stimulation on pregnant rats and fetuses. Rats in the stimulation group were stimulated 7 hours every day from Day 4 to Day 20 of gestation. The results showed that no 
abortions were observed and no significant difference between the stimulation group $(2.27 \pm 0.51 \mathrm{~g})$ and the sham group $(2.13 \pm 0.51 \mathrm{~g} ; p=0.91)$ in terms of fetal body weight [52]. Thus, it was concluded that termination of pregnancy is not advised for prospective mothers when electrical stimulation has been performed unknowingly in early pregnancy.

Khunda et al. published a retrospective study about pregnancy in patients with chronic urinary retention syndrome who underwent a two-stage SNM implantation. A total of 10 patients with 13 pregnancies were reviewed. The SNM was switched off in 10 of the 13 pregnancies, with CUR recurring in 9 of the 10 pregnancies and recurrent urinary tract infections (UTI) occurring in 4 of these pregnancies (more than 3 UTI during the pregnancy). Those in whom the device was left on continued to void normally. One woman had a firsttrimester miscarriage, eight pregnancies went to term, and four deliveries were premature. Cesarean section was performed in eight pregnancies for obstetric reasons. Four pregnancies resulted in a vaginal delivery. There were no congenital anomalies reported. Following delivery, four of nine women experienced dysfunction of their SNM device when it was switched back on. They suggested the option of keeping the SNM on during pregnancy to be considered, and cesarean section should only be performed for obstetric reasons [53•].

Wiseman et al. obtained data on six pregnant women with SNM. In five patients, the stimulator was deactivated between weeks 3 and 9 of gestation, after which two with a history of urinary retention had urinary tract infection. In another case, stimulation was discontinued 2 weeks before conception. The only noted complication developed in a pregnancy in which birth was premature at 34 weeks. Three patients underwent normal vaginal delivery, including one in whom subsequent implant reactivation did not resolve voiding dysfunction. In three cases, elective cesarean section was performed. One with urinary retention had to have the device switched back on at 19/40 weeks due to difficult catheterization without any complications during pregnancy. All neonates in the series were healthy [54].

Women with electrical stimulation devices for pelvic health conditions who become pregnant may simply turn off their devices when considering and during pregnancy due to deficiency of the clinical evidence in pregnancy.

\section{Conclusions}

SNM is a promising solution to many complicated and chronic female pelvic dysfunction. SNM is effective for intractable urge incontinence, urgency-frequency, nonobstructive urinary retention, and fecal incontinensace and should be consider as a second-line treatment before irreversible major surgery. Future indications for SNM may include IC/PBS, chronic pelvic pain, chronic constipation, and female sexual dysfunction.
There are too few studies regarding SNM in pregnancy to guide best practices. However, the pregnant subject with SNM should consult with her physician and may want to consider having active stimulation of her SNM therapy only if the benefits of the therapy outweigh the risks.

\section{Compliance with Ethics Guidelines}

Conflict of Interest Baydaa Al-Sannan, Mai Banakhar, and Magdy M. Hassouna declare that they have no conflict of interest.

Human and Animal Rights and Informed Consent This article does not contain any studies with human or animal subjects performed by any of the authors.

\section{References}

Papers of particular interest, published recently, have been highlighted as:

- Of importance

1. Juenemann KP, Lue TF, Schmidt RA, Tanagho EA. Clinical significance of sacral and pudendal nerve anatomy. J Urol. 1988;139(1):74 80 .

2. Shaker HS, Hassouna M. Sacral root neuromodulation in idiopathic nonobstructive chronic urinary retention. J Urol. 1998;159(5):1476-8.

3. Abrams P, Blaivas JG, Fowler CJ, Fourcroy JL, Macdiarmid SA, Siegel SW, et al. The role of neuromodulation in the management of urinary urge incontinence. BJU Int. 2003;91(4):355-9.

4. Schultz-Lampel D, Jiang C, Lindstrom S, Thuroff JW. Experimental results on mechanisms of action of electrical neuromodulation in chronic urinary retention. World J Urol. 1998;16(5):301-4.

5. Leng WW, Chancellor MB. How sacral nerve stimulation neuromodulation works. Urol Clin N Am. 2005;32(1):11-8.

6. Fowler CJ, Swinn MJ, Goodwin RJ, Oliver S, Craggs M. Studies of the latency of pelvic floor contraction during peripheral nerve evaluation show that the muscle response is reflexly mediated. J Urol. 2000;163(3):881-3.

7. Bemelmans BL, Mundy AR, Craggs MD. Neuromodulation by implant for treating lower urinary tract symptoms and dysfunction. Eur Urol. 1999;36(2):81-91.

8. Vitton V, Abysique A, Gaige S, Leroi AM, Bouvier M. Colonosphincteric electromyographic responses to sacral root stimulation: evidence for a somatosympathetic reflex. Neurogastroenterol Motil. 2008;20:407-16.

9. Peeren F, Hoebeke P, Everaert K. Sacral nerve stimulation: Interstim therapy. Expert Rev Med Devices. 2005;2(3):253-8.

10. - Mai Banakhar TA-SaMH. Challenges in Sacral Neuromodulation. Topics in neuromodulation treatment 2012, chapter 3:35-62. A review chapter about the mechanism of action, techniques, indications, and complications of SNM concluded that sacral neuromodulation offers minimally invasive treatment for voiding dysfunction. Special attention is given to pregnant patients. Precautions should be followed to avoid complications in both pregnancy and MRI procedures in sacral neuromodulation patients.

11. • Al-Shaiji TF, Banakhar M, Hassouna MM. Pelvic electrical neuromodulation for the treatment of overactive bladder symptoms. Adv Urol. 2011;2011:757454. This paper provides a review on the indications, possible mechanisms of action, surgical aspects and 
possible complications, and safety issues of this technique. SNM is an effective treatment modality for patients with refractory $O A B$ and should be offered before applying more invasive, irreversible treatments. The procedure is safe and minimally invasive involving oneor two-stage implantation.

12. Pannek J, Grigoleit U, Hinkel A. Bacterial contamination of test stimulation leads during percutaneous nerve stimulation. Urology. 2005;65(6):1096-8.

13. Borawski KM, Foster RT, Webster GD, Amundsen CL. Predicting implantation with a neuromodulator using two different test stimulation techniques: a prospective randomized study in urge incontinent women. Neurourol Urodyn. 2007;26(1):14-8.

14. Peters KM, Carey JM, Konstandt DB. Sacral neuromodulation for the treatment of refractory interstitial cystitis: outcomes based on technique. Int Urogynecol J Pelvic Floor Dysfunct. 2003;14(4):223-8. discussion 228.

15. Everaert K, Kerckhaert W, Caluwaerts H, Audenaert M, Vereecke H, De Cuypere G, et al. A prospective randomized trial comparing the 1stage with the 2-stage implantation of a pulse generator in patients with pelvic floor dysfunction selected for sacral nerve stimulation. Eur Urol. 2004;45(5):649-54.

16. Janknegt RA, Hassouna MM, Siegel SW, Schmidt RA, Gajewski JB, Rivas DA, et al. Long-term effectiveness of sacral nerve stimulation for refractory urge incontinence. Eur Urol. 2001;39(1):101-6.

17. DasGupta R, Fowler CJ. The management of female voiding dysfunction: Fowler's syndrome - a contemporary update. Curr Opin Urol. 2003;13(4):293-9.

18. Schmidt RA, Jonas U, Oleson KA, et al. Sacral nerve stimulation for the treatment of refractory urinary urge incontinence. J Urol. 1999;162:352-7.

19. • van Kerrebroeck PE, van Voskuilen AC, Heesakkers JP, Lycklama a Nijholt AA, Siegel S, Jonas U, et al. Results of sacral neuromodulation therapy for urinary voiding dysfunction: outcomes of a prospective, worldwide clinical study. J Urol. 2007;178(5):2029-34. A review study in SNM for lower urinary tract dysfunction has been successfully used in approximately 26,000 patients with various forms of lower urinary tract dysfunction, including urgency, frequency, and urgency incontinence as well as nonobstructive urinary retention. Found to be effective in approximately $70 \%$ of the patients who have been implanted with a permanent system.

20. Brazzelli M, Murray A, Fraser C. Efficacy and safety of sacral nerve stimulation for urinary urge incontinence: a systematic review. J Urol. 2006;175(3 Pt 1):835-41.

21. • Leong RK, De Wachter SG, van Kerrebroeck PE. Current information on sacral neuromodulation and botulinum toxin treatment for refractory idiopathic overactive bladder syndrome: a review. Urol Int. 2010;84(3):245-53. This review attempts to provide an update on the current position of $S N M$ and botulinum toxin in the second-line management of adults with idiopathic OAB, based on the available clinical evidence concerning the efficacy and safety.

22. Hassouna MM, Siegel SW, Nyeholt AA, et al. Sacral neuromodulation in the treatment of urgency-frequency symptoms: a multicenter study on efficacy and safety. J Urol. 2000;163:1849-54.

23. Tanagho EA, Schmidt RA, Orvis BR. Neural stimulation for control of voiding dysfunction: a preliminary report in 22 patients with serious neuropathic voiding disorders. J Urol. 1989;142(2 Pt 1):340-5.

24. - Denzinger S, Nowrotek A, Weingart P, Burger M, Wieland WF, Rossler W, Otto W: Does sacral neuromodulation lead to relevant reduction in the need for intermittent catheterization? A single-center experience on patients with chronic urinary retention. Neuromodulation : journal of the International Neuromodulation Society 2012, 15(6):586-591; discussion 591. Twenty patients suffered from idiopathic or neurogenic urinary retention for a median 60 months before SNM were included. Ninety percent of the stimulated patients showed significant success with implantation of SNM in postvoid residual and number of intermittent catheterizations. Their conclusion is that SNM can be a successful and secure second-line therapy option for patients with chronic urinary retention.

25. Wexner SD, Coller JA, Devroede G, Hull T, McCallum R, Chan M, et al. Sacral nerve stimulation for fecal incontinence: results of a 120patient prospective multicenter study. Ann Surg. 2010;251(3):441-9.

26. Mellgren A, Wexner SD, Coller JA, Devroede G, Lerew DR, Madoff $\mathrm{RD}$, et al. Long-term efficacy and safety of sacral nerve stimulation for fecal incontinence. Dis Colon Rectum. 2011;54(9):1065-75.

27. • Uludag O, Melenhorst J, Koch SM, van Gemert WG, Dejong CH, Baeten CG. Sacral neuromodulation: long-term outcome and quality of life in patients with faecal incontinence. Colorectal Dis Off J Assoc Coloproctology Great Britain Ireland. 2011;13(10):1162-6. A prospective study assessed the long-term outcome and quality of life in the first 50 patients treated by permanent SNM for faecal incontinence. During a median follow-up of 7.1 years, 42 patients had an improvement in continence of more than $50 \%$. Initial improvement in continence with SNM was sustained in the majority of patients, with an overall success rate of $80 \%$ after a permanent implant at 7 years.

28. - Leroi AM, Lenne X, Dervaux B, Chartier-Kastler E, Mauroy B, Normand LL, et al. Outcome and cost analysis of sacral nerve modulation for treating urinary and/or fecal incontinence. Ann Surg. 2011;253(4):720-32. A prospective, multicenter cohort study that included 369 consecutive patients with urge urinary and/or fecal incontinence. The duration of follow-up was 24 months, and costs were estimated from the national health perspective. SNM significantly improved the continence status and quality of life in patients with urge urinary and/or fecal incontinence compared to alternative treatments. They conclude that SNM is a cost-effective treatment for urge urinary and/or fecal incontinence.

29. Gillenwater JY, Wein AJ. Summary of the National Institute of Arthritis, Diabetes, Digestive and Kidney Diseases Workshop on Interstitial Cystitis, National Institutes of Health, Bethesda, Maryland, August 28-29, 1987. J Urol. 1988;140(1):203-6.

30. Abrams P, Cardozo L, Fall M, Griffiths D, Rosier P, Ulmsten U, et al. The standardisation of terminology of lower urinary tract function: report from the Standardisation Sub-committee of the International Continence Society. Neurourol Urodyn. 2002;21(2):167-78.

31. van de Merwe JP, Nordling J, Bouchelouche P, Bouchelouche K, Cervigni M, Daha LK, et al. Diagnostic criteria, classification, and nomenclature for painful bladder syndrome/interstitial cystitis: an ESSIC proposal. Eur Urol. 2008;53(1):60-7.

32. CL. P. Interstitial cystitis. In: Ostergard DR, Bent AE, editors. Urogynaecology and urodynamics. Baltimore: Williams \& Wilkins Co 1996(4th ed.).

33. Maher CF, Carey MP, Dwyer PL, Schluter PL. Percutaneous sacral nerve root neuromodulation for intractable interstitial cystitis. J Urol. 2001;165(3):884-6.

34. - Srivastava D. Efficacy of sacral neuromodulation in treating chronic pain related to painful bladder syndrome/interstitial cystitis in adults. J Anaesthesiol Clin Pharmacol. 2012;28(4):428-35. Review study of 170/244 patients successful at the trial stage evaluated the efficacy and safety of sacral neuromodulation in treating chronic pelvic pain related to painful bladder syndrome/interstitial-cystitis. Decrease in visual analogue pain scores of $49 \%$ in sacral nerve stimulation and $29 \%$ in pudendal nerve stimulation group at 6 months follow-up were seen. Randomised, controlled trial and case series/case reports demonstrate a reduction of pain symptoms of Painful bladder syndrome following sacral neuromodulation.

35. - Marinkovic SP, Gillen LM, Marinkovic CM. Minimum 6-year outcomes for interstitial cystitis treated with sacral neuromodulation. Int Urogynecol J. 2011;22(4):407-12. An observational, retrospective, case-controlled study involved 34 female patients underwent SNM implantation. Both the preop/postop pelvic pain and urgency/ frequency scores and preop/postop visual analog pain scale were reduced significantly with a mean follow-up of $86 \pm 9.8$ months. With 
a minimum of 6-year follow-up, SNM provides adequate improvement for the symptoms of recalcitrant interstitial cystitis.

36. - Gajewski JB, Al-Zahrani AA. The long-term efficacy of sacral neuromodulation in the management of intractable cases of bladder pain syndrome: 14 years of experience in one centre. BJU Int. 2011;107(8):1258-64. Retrospective study included 78 patients who fulfilled the clinical criteria for BPS and failed conservative management before considering SNM implantation. Good long-term success of the SNM was seen in $72 \%$ of the patients. SNM is an effective treatment to control the symptoms of BPS. It should be considered before any major invasive surgical intervention if conservative measures have failed.

37. • Martellucci J, Naldini G, Del Popolo G, Carriero A. Sacral nerve modulation in the treatment of chronic pain after pelvic surgery. Colorectal Dis. 2012;14(4):502-7. Prospective study evaluated the efficacy of SNM for chronic pelvic pain after pelvic or anal surgery for benign disease. Seventeen consecutive patients suffering from chronic pelvic pain underwent evaluation for sacral nerve modulation in three pelvic floor units. Forty-seven percent of patients fulfilled the criteria for definitive implantation and were followed. Visual analog pain score pain levels fell from 8.2 preoperatively to 1.9, 2.1, 2.0, and 1.8 at 6, 12, 24, and 36 months. SNM seems to be effective over time in some patients with chronic pain related to previous surgery.

38. Holzer B, Rosen HR, Novi G, Ausch C, Holbling N, Hofmann $\mathrm{M}$, et al. Sacral nerve stimulation in patients with severe constipation. Dis Colon Rectum. 2008;51(5):524-9. discussion 529530 .

39. - Kamm MA, Dudding TC, Melenhorst J, Jarrett M, Wang Z, Buntzen S, et al. Sacral nerve stimulation for intractable constipation. Gut. 2010;59(3):333-40. A prospective study at five European sites of patients who failed conservative treatment underwent 21 days of test stimulation. Forty-five of 62 proceeded to chronic stimulation; $87 \%$ of these achieved treatment success. Defecation frequency and days per week evacuation increased significantly, with a significant decrease in time spent toileting, straining, perception of incomplete evacuation, and subjective rating of abdominal pain and bloating. SNS is effective for the treatment of idiopathic slow and normal transit constipation resistant to conservative treatment.

40. Jadav AM, Wadhawan H, Jones GL, Wheldon LW, Radley SC, Brown SR. Does sacral nerve stimulation improve global pelvic function in women? Colorectal disease: the official journal of the Association of Coloproctology of Great Britain and Ireland 2013.

41. Lombardi G, Mondaini N, Macchiarella A, Cilotti A, Del Popolo G. Clinical female sexual outcome after sacral neuromodulation implant for lower urinary tract symptom (LUTS). J Sex Med. 2008;5(6):1411-7.

42. - Signorello D, Seitz CC, Berner L, Trenti E, Martini T, Galantini A, et al. Impact of sacral neuromodulation on female sexual function and his correlation with clinical outcome and quality of life indexes: a monocentric experience. J Sex Med. 2011;8(4):1147-55. Prospectively assesses changes in sexual function, clinical outcome, and quality of life after SNM in female patients with overactive bladder $(O A B)$. Sixteen of 30 female patients with $O A B$ considered eligible for SNM. Regarding sexuality, the total Female Sexual Function Index score was $27.9 \%$ and $29.3 \%$ at midterm and last follow-up visits. The results demonstrate that improvement in the quality of sexual function in female patients with $O A B$ correlates with improvement in urinary symptoms.

43. • Caremel R, Nouhaud FX, Leroi AM, Ruffion A, Michot F, Damon $\mathrm{H}$, et al. [Results of sacral neuromodulation on the urinary and fecal incontinence and sexuality in 20 women suffering from a double incontinence]. Progres en urologie. 2012;22(7):424-32. Twenty sexually active patients suffering from double incontinence were considered eligible. Fifty percent of patients were improved for two incontinences and $45 \%$ improves in quality of sexual activity. The numbers of urinary and faecal episodes of incontinence are decreased respectively for $50 \%$ and $15 \%$ patients during sexual activity. This study confirms the effectiveness of NMS for the treatment of double incontinence and showed a positive impact on sexuality of these patients.

44. Zabihi N, Mourtzinos A, Maher MG, Raz S, Rodriguez LV. The effects of bilateral caudal epidural S2-4 neuromodulation on female sexual function. Int Urogynecol J Pelvic Floor Dysfunct. 2008;19(5):697-700.

45. Ramsay LB, Wright Jr J, Fischer JR. Sacral neuromodulation in the treatment of vulvar vestibulitis syndrome. Obstet Gynecol. 2009;114(2 Pt 2):487-9.

46. - Marcelissen T, Van Kerrebroeck P, de Wachter S. Sacral neuromodulation as a treatment for neuropathic clitoral pain after abdominal hysterectomy. Int Urogynecol J. 2010;21(10):1305-7. A case report of 51-year-old patient who presented with symptoms of lower urinary tract dysfunction and clitoral pain after an abdominal hysterectomy. She was offered SNM as a treatment for her voiding symptoms. During test stimulation, she experienced only moderate improvement in voiding symptoms but a striking improvement in pain symptoms. This report suggests that SNM may be effective in patients with neuropathic pelvic pain.

47. - Wehbe SA, Whitmore K, Kellogg-Spadt S: Urogenital complaints and female sexual dysfunction (part 1). The journal of sexual medicine 2010, 7(5):1704-1713; quiz 1703, 1714-1705. This study was designed to identify the relationship between sexual dysfunction and common urological disorders in women and to describe appropriate treatment strategies to improve the women's quality of life. Sexual dysfunction is a common, underestimated, and untreated complaint in women with urologic disorders. Identifying sexual complaints and treating the underlying etiologies can result in significant improvement in a woman's quality of life.

48. Siegel SW, Catanzaro F, Dijkema HE, Elhilali MM, Fowler CJ, Gajewski JB, et al. Long-term results of a multicenter study on sacral nerve stimulation for treatment of urinary urge incontinence, urgency-frequency, and retention. Urology. 2000;56(6 Suppl 1):87-91.

49. Hijaz A, Vasavada SP, Daneshgari F, Frinjari H, Goldman H, Rackley R. Complications and troubleshooting of two-stage sacral neuromodulation therapy: a single-institution experience. Urology. 2006;68(3):533-7.

50. Spinelli M, Giardiello G, Gerber M, et al. New sacral neuromodulation lead for percutaneous implantation using local anesthesia: description and first experience. J Urol. 2003;170:19051907.

51. Pettit P. Current opinion: complications and troubleshooting of sacral neuromodulation. Int Urogynecol J. 2010 Dec;21 Suppl 2:S491-6.

52. Wang Y, Hassouna MM. Electrical stimulation has no adverse effect on pregnant rats and fetuses. J Urol. 1999;162(5):1785-7.

53. - Khunda A, Karmarkar R, Abtahi B, Gonzales G, Elneil S. Pregnancy in women with Fowler's syndrome treated with sacral neuromodulation. International urogynecology journal 2013. A retrospective study of 13 pregnancies in 10 patients with Fowler's syndrome who underwent SNM implantation filled a standard questioner. The SNM switched off in 10 of the 13 pregnancies, chronic urinary retention recurring in 9 of the 10 pregnancies, and recurrent UTI in 4 of these pregnancies. Those in whom the device was left on continued to void normally. Turing off the SNM during pregnancy results in recurrence of chronic urinary retention and an increased risk of recurrent UTI associated with preterm delivery. The option of keeping the SNM on during pregnancy therefore should be considered.

54. Wiseman OJ, v d Hombergh U, Koldewijn EL, Spinelli M, Siegel SW, Fowler CJ. Sacral neuromodulation and pregnancy. The Journal of urology 2002, 167(1):165-168.

55. bullock TL sS. Sacral neuromodulation for voiding dysfunction in statskin D atlas of bladder disease 2010.

56. Williams ER, Siegel SW. Procedural techniques in sacral nerve modulation. Int Urogynecol J. 2010;21 Suppl 2:S453-60. 